\title{
Particle size distribution of nitrated and oxygenated polycyclic aromatic hydrocarbons (NPAHs and OPAHs) on traffic and suburban sites of a European megacity: Paris (France)
}

\author{
J. Ringuet ${ }^{1,2,3}$, E. Leoz-Garziandia ${ }^{1}$, H. Budzinski ${ }^{2,3}$, E. Villenave ${ }^{2,3}$, and A. Albinet ${ }^{1}$ \\ ${ }^{1}$ Institut National de l'Environnement industriel et des RISques (INERIS), Parc technologique Alata BP2, \\ Verneuil en Halatte, France \\ ${ }^{2}$ University of Bordeaux, EPOC-OASU, UMR5805, Talence, France \\ ${ }^{3}$ CNRS, EPOC, UMR5805, Talence, France
}

Correspondence to: A. Albinet (alexandre.albinet@gmail.com)

Received: 25 April 2012 - Published in Atmos. Chem. Phys. Discuss.: 6 June 2012

Revised: 2 August 2012 - Accepted: 13 September 2012 - Published: 28 September 2012

\begin{abstract}
The size distribution of particulate nitrated and oxygenated polycyclic aromatic hydrocarbons (NPAHs and OPAHs) was determined during two field campaigns at a traffic site in summer 2010 and at a suburban site during the MEGAPOLI (Megacities: Emissions, urban, regional and Global Atmospheric POLlution and climate effects, and Integrated tools for assessment and mitigation) experiment in summer 2009. Both, OPAHs and NPAHs were strongly associated $(>85 \%)$ to fine particles $\left(D_{\mathrm{p}}<2.5 \mu \mathrm{m}\right)$ increasing the interest of their study on a sanitary point of view. Results showed really different NPAH and OPAH particle size distributions between both sites. At traffic site, clearly bimodal (notably for NPAHs) particle size distributions $\left(D_{\mathrm{p}}=0.14\right.$ and $1.4 \mu \mathrm{m}$ ) were observed, while the particle size distributions were more scattered at the suburban site, especially for OPAHs. Bimodal particle size distribution observed at traffic site for the NPAH could be assigned to the vehicle emissions and the particle resuspension. Broadest distribution observed at the suburban site could be attributed to the mass transfer of compounds by volatilization/sorption processes during the transport of particles in the atmosphere. Results also showed that the combination of the study of particle size distributions applied to marker compounds (primary: 1-nitropyrene; secondary: 2-nitrofluoranthene) and to NPAH or OPAH chemical profiles bring some indications on their primary and/or secondary origin. Indeed, 1,4-anthraquinone seemed only primary emitted by vehicles while 7-nitrobenz[a]anthracene, benz[a]antracen7,12-dione and benzo[b]fluorenone seemed secondarily formed in the atmosphere.
\end{abstract}

\section{Introduction}

Numerous studies had been demonstrated the relationship between particle size and health effect (Oberdörster et al., 2005; Berico et al., 1997). Particulate matter may penetrate in the respiratory system more or less deeply depending on the particle size. Coarse particles $\left(D_{\mathrm{p}}>2.5 \mu \mathrm{m}\right)$ are blocked in the extra thoracic region while, ultrafine ones $\left(D_{\mathrm{p}}<0.1 \mu \mathrm{m}\right)$ are able to reach the pulmonary alveoli causing serious health damages (Oberdörster et al., 2005; Berico et al., 1997). The toxicity of these particles is linked to their size, but also to the chemicals which are adsorbed on them. Many toxic compounds are associated to aerosol particles such as polycyclic aromatic hydrocarbons (PAHs) emitted in the atmosphere by combustion processes and their oxygenated and nitrated derivatives namely, OPAHs and NPAHs. These last compounds are both, emitted primarily by combustion sources and formed in the atmosphere by photo-oxidation processes of parent PAHs with atmospheric oxidants (e.g. $\mathrm{O}_{3}, \mathrm{NO}_{2}$, $\mathrm{N}_{2} \mathrm{O}_{5}, \mathrm{OH}$ and $\mathrm{NO}_{3}$ radicals) (Vione et al., 2004; Pitts Jr. et al., 1978; Zhang et al., 2011; Albinet et al., 2007a; Arey et al., 1986; Atkinson, 1990 and references therein).

Particle size distribution of PAHs was largely investigated in numerous studies (e.g. Allen et al., 1996; Miguel et al., 2004; Kawanaka et al., 2004, 2008; Albinet et al., 2008a; Saarnio et al., 2008; Schnelle-Kreis et al., 2001; Duan et al., 2005; Venkataraman and Friedlander, 1994; Venkataraman et al., 2002). These studies, conducted in various countries, 
showed that the PAH particle size distribution depended on several parameters, such as season or particle aging.

Due to their recognized or potential mutagenic activity (Arey et al., 1988; Durant et al., 1996; Ishii et al., 2000; Pedersen et al., 2004, 2005), the study of PAH derivatives according to the particle size distribution is of prime interest. However, to date, only 8 authors reported results on the size distribution of NPAHs (Ladji et al., 2009; Hayakawa et al., 1995b; Albinet et al., 2008a; Cecinato et al., 1999; Di Filippo et al., 2010; Hayakawa et al., 1995a; Jinhui and Lee, 2000; Kawanaka et al., 2004, 2008; Teixeira et al., 2011), and only 4 papers focused on the particle size distribution of OPAHs (Albinet et al., 2008a; Allen, 1997; Allen et al., 1997; Ladji et al., 2009).

This paper presents results from the study of the particle size distribution of OPAHs and NPAHs for two sites of different typology: traffic and suburban. The purpose of this study was to apprehend the link between the particle size distribution of 18 NPAHs and 9 OPAHs, the sanitary impact and the primary and/or secondary origin of these compounds.

\section{Experimental section}

\subsection{Sampling sites}

The suburban site was located in Palaiseau (France) at twenty kilometres in the south-west of Paris $\left(48^{\circ} 2^{\prime} \mathrm{N}, 2^{\circ} 14^{\prime} \mathrm{E}\right)$. Samplings were done continuously during the MEGAPOLI (Megacities: Emissions, urban, regional and Global Atmospheric POLlution and climate effects, and Integrated tools for assessment and mitigation) (http://megapoli.dmi. dk) summer experiment on 15 to 31 July 2009. This site was potentially under the influence of Paris plume and far from any other major pollution source. No precipitation occurred during the sampling period. The weather was cloudy with bright intervals and average temperature was about $18^{\circ} \mathrm{C}$. During all the sampling campaign, observed $\mathrm{PM}_{10}$ and $\mathrm{NO}_{\mathrm{x}}$ atmospheric concentrations were quite low (15 and $13 \mu \mathrm{g} \mathrm{m}^{-3}$, respectively, in average), and $\mathrm{O}_{3}$ concentrations were moderate $\left(75 \mu \mathrm{g} \mathrm{m}^{-3}\right)$.

The traffic site was located in Paris (France, Airparif's air quality network station "Porte d'Auteil" (48 $51^{\prime} \mathrm{N}$, $\left.2^{\circ} 15^{\prime} \mathrm{E}\right)$ ). Samplings were done continuously (on 6 to 13 September 2010). The instrumented station was situated at $2 \mathrm{~m}$ from the heavily trafficked ring road (>220000 vehicles/day, $75 \%$ diesel passenger cars, www.airparif.fr). During the sampling period, the weather was quite variable (cloudy with rainfall episodes the first days and sunny for the rest of the sampling period) and the average temperature was about $19^{\circ} \mathrm{C}$. Atmospheric $\mathrm{NO}_{\mathrm{x}}$ and $\mathrm{PM}_{10}$ concentrations were higher than at the suburban site $\left(265\right.$ and $40 \mathrm{\mu g} \mathrm{m}^{-3}$, respectively), and $\mathrm{O}_{3}$ concentration levels were lower than the quantification limit $\left(<2 \mu \mathrm{g} \mathrm{m}^{-3}\right)$.

\subsection{Sample collection}

Two types of samplers were used during these field campaigns. Aerosol particle samples were collected on a quartz fibre filter (Whatman QMA, Ø $150 \mathrm{~mm}$ ) previously fired for $2 \mathrm{~h}$ at $500{ }^{\circ} \mathrm{C}$, using a high volume sampler equipped with a $\mathrm{PM}_{10}$ sampling head (Digitel DA-80, $30 \mathrm{~m}^{3} \mathrm{~h}^{-1}$ ). Sampling duration was $12 \mathrm{~h}$ (from 7:00 a.m.). Particle size distributions were established with a micro-orifice uniform deposit impactor (from 0.01 to $18 \mu \mathrm{m}$ ) (MOUDI $120 \mathrm{II}, \mathrm{MSP}$ corp., $\left.1.8 \mathrm{~m}^{3} \mathrm{~h}^{-1}\right)$. Details on the size classes are reported in the Supplement (Table S1). Particles were collected on aluminium foils (MSP corp., $\varnothing 47 \mathrm{~mm}$ ) placed on each impaction stage and a quartz fibre filter (Whatman QMA, $\varnothing$ $47 \mathrm{~mm}$ ) was used as backup filter. All filters and aluminium foils were previously fired for $2 \mathrm{~h}$ at $500^{\circ} \mathrm{C}$. Sampling duration was $24 \mathrm{~h}$ (from 7:00 a.m.). After collection, filters were wrapped in aluminium foil, sealed in polyethylene bags and samples from the MOUDI were stored in Petri dishes (Pall, Analyslide) and placed in opaque hermetic bags. All samples were stored at $-22^{\circ} \mathrm{C}$ until analysis.

\subsection{Analytical procedures}

Reagents used, their degrees of purity, and the supplier data are reported in the Supplement. Detailed analytical procedures are also described.

Prior to extraction, 1-nitropyrene-d9 was added as a surrogate standard for NPAHs and OPAHs quantification. Filter samples and aluminium foils were extracted by pressurised solvent extraction using $\mathrm{CH}_{2} \mathrm{Cl}_{2}$ as the solvent (Dionex, ASE 200). Due to low concentrations in ambient air, all the MOUDI's impaction media (aluminium foils) of the same particle size range were extracted together in order to have a sufficient amount of matter to perform the quantification of OPAHs and NPAHs. For the traffic site, it represented 7 impaction media corresponding to 7 sampling days (from the 7 to the 13 September 2012). For the suburban site, particle size distributions obtained are a combination of 16 impaction media sampled continuously (from the 15 to the 31 July 2009). Prior to analyses, extracts were purified using alumina and silica SPE (solid phase extraction). Residues were then dissolved in isooctane and analysed by GC/NICI-MS (gas chromatography with negative ion chemical ionisationmass spectrometry detection). Entire analytical procedures used were described previously (Albinet et al., 2006) and detailed in the Supplement. Overall 18 NPAHs and 9 OPAHs were quantified with this procedure.

\subsection{Quality assurance}

The analytical procedure for NPAH and OPAH was validated by the analysis of the NIST SRM 1649a (standard reference material, urban dust). Recovery rates were in the range 14-84\% for NPAHs (1-nitronaphthalene and 
Table 1. Comparison of the atmospheric particulate NPAH and OPAH concentrations determined with both types of samplers.

\begin{tabular}{|c|c|c|c|c|c|c|}
\hline & \multirow[t]{2}{*}{$\mathrm{MW}\left(\mathrm{g} \mathrm{mol}^{-1}\right)$} & \multicolumn{2}{|c|}{ Traffic } & \multicolumn{2}{|c|}{ Suburban } & \multirow[b]{2}{*}{$\begin{array}{c}\text { Uncertainties of } \\
\text { measurement* }(\%)\end{array}$} \\
\hline & & DA-80 & $\begin{array}{l}\text { MOUDI } \\
\text { NPAHs }\end{array}$ & $\begin{array}{r}\mathrm{DA}-80 \\
\left.\mathrm{pg} \mathrm{m}^{-3}\right)\end{array}$ & MOUDI & \\
\hline 1-Nitronaphtalene (1-Nnaph) & 173 & 6.1 & 5.5 & 0.2 & 0.2 & 53 \\
\hline 2-Nitronaphtalene (2-Nnaph) & 173 & 3.1 & 2.8 & 0.0 & 0.2 & 91 \\
\hline 2-Nitrofluorene (2-Nfluo) & 211 & 0.4 & nd & nd & nd & 63 \\
\hline 9-Nitroanthracene (9-NA) & 223 & 29.2 & 6.8 & 6.1 & 0.8 & 105 \\
\hline 9-Nitrophenanthrene (9-Nphen) & 223 & 4.9 & 2.0 & nd & 0.1 & 182 \\
\hline 3-Nitrophenanthrene (3-Nphen) & 223 & 7.8 & 5.0 & 0.6 & 0.2 & 308 \\
\hline $2+3$-Nitrofluoranthene $(2+3-\mathrm{Nflt})$ & 247 & 15.8 & 9.4 & 11.7 & 4.6 & 105 \\
\hline 1-Nitropyrene (1-NP) & 247 & 72.6 & 51.3 & 1.6 & 1.4 & 83 \\
\hline 2-Nitropyrene (2-NP) & 247 & 7.9 & 29.8 & 0.8 & 1.8 & 120 \\
\hline 4-Nitropyrene (4-NP) & 247 & 2.9 & 2.1 & nd & 0.1 & 292 \\
\hline 7-Nitrobenzo[a]anthracene (7-NB[a]A) & 273 & 5.9 & 3.3 & 0.7 & 1.4 & 87 \\
\hline 6-Nitrochrysene (6-NChr) & 273 & 0.3 & nd & nd & nd & 177 \\
\hline 1,3-Dinitropyrene (1,3-DNP) & 292 & 1.2 & 0.7 & 0.1 & nd & 96 \\
\hline 1,6-Dinitropyrene (1,6-DNP) & 292 & 0.1 & nd & nd & nd & 98 \\
\hline 1,8-Dinitropyrene (1,8-DNP) & 292 & 1.8 & 1.3 & 0.4 & nd & 113 \\
\hline 1-Nitrobenzo[a]pyrene (1-NB[a]P) & 297 & 0.1 & 0.1 & nd & nd & 107 \\
\hline 3-Nitrobenzo[a]pyrene (3-NB[a]P) & 297 & 0.3 & 0.8 & nd & nd & 107 \\
\hline \multirow[t]{2}{*}{ 6-Nitrobenzo[a]pyrene (6-NB[a]P) } & 297 & 9.9 & 1.4 & 0.4 & 0.1 & 67 \\
\hline & \multicolumn{6}{|c|}{ OPAHs $\left(\mathrm{pg} \mathrm{m}^{-3}\right)$} \\
\hline 1-Naphtaldehyde (1-Naph) & 156 & 5.2 & 5.1 & 0.2 & nd & 103 \\
\hline 9-Fluorenone (9-Fluo) & 180 & 73.5 & 43.5 & 7.8 & 3.6 & 93 \\
\hline 9-Phenanthrenecarboxaldehyde (9-Phen) & 206 & 207.0 & 164.4 & 2.1 & 0.4 & 93 \\
\hline 9,10-Anthraquinone (9,10-Ant) & 208 & 659.8 & 82.0 & 55.7 & 6.6 & 51 \\
\hline 1,4-Anthraquinone (1,4-Ant) & 208 & 122.0 & 257.2 & 0.2 & nd & 85 \\
\hline Benzo[a]fluorenone (B[a]Fone) & 230 & 166.5 & 206.6 & 15.6 & 2.3 & 88 \\
\hline Benzo[b]fluorenone (B[b]Fone) & 230 & 151.3 & 18.0 & 3.0 & 2.6 & 73 \\
\hline Benzanthrone (Benz-one) & 230 & 46.6 & 6.6 & 3.4 & 4.3 & 122 \\
\hline Benz[a]anthracene-7,12-dione (B[a]A-7,12-dione) & 258 & 45.2 & 41.7 & 11.5 & 4.9 & 84 \\
\hline
\end{tabular}

* uncertainties of measurement evaluated for the DA-80 with the GUM (Guide to the expression of Uncertainty in Measurement) approach. Details are reported elsewhere (Ringuet et al., 2012a) and in the Supplement.

7-nitrobenz[a]anthracene, respectively), and from 5\% (1naphthaldehyde) to $83 \%$ (benzo[b]fluorenone) for OPAHs; The repeatability of the entire analytical procedure (reproducibility) was about $15 \%$ on average, evaluated using the NIST SRM 1649a and b (urban dust) (Albinet et al., 2006). Analytical blanks were realized at each step (extraction, purification and analysis) of each analysis series $(n=4)$. Field blanks (i.e. sampling media exposed without filtration) were done every two days for the DA- $80(n=12)$ and every day for the MOUDI, at each site ( 1 stage per day; $n=24$, extracted in two sets). OPAH and NPAH concentrations were corrected from the highest blank value obtained in the analytical process. Overall, the blank levels obtained during both field campaigns were in the range $<$ LOD to below $10 \%$ of the average individual OPAH and NPAH concentrations.

\section{Results}

\subsection{Comparison of NPAH and OPAH concentrations determined with both sampler types}

Given that traffic and suburban sites were instrumented with two types of samplers (cascade impactor and high volume sampler), a comparison of the particulate OPAH and NPAH concentrations determined with both sampling systems could be realised by summing the concentrations of all the impactor stages and averaging concentrations of the all 12-hour total filtration samples (DA-80) (Table 1). Overall, concentrations obtained with both samplers were of the same order of magnitude and could be considered as equivalent, in regard to the uncertainties of measurement evaluated for the DA80, using the GUM approach (global uncertainty of measurement) (Table 1) (Ringuet et al., 2012a; Macé et al., 2010). Note that, global uncertainties of measurement are 
in the range $51-308 \%$, with about $90 \%$ due to the analytical procedure. The fact that certified concentration values do not exist for all the studied compounds increases artificially the global uncertainty (see the Supplement for details of the calculation). By neglecting this parameter, the uncertainties are in the range 11-140\%. By comparison, total uncertainty of measurement of benzo[a]pyrene $(\mathrm{B}[\mathrm{a}] \mathrm{P})$ is about $40 \%$ (Macé et al., 2010) $(<50 \%$ in agreement with European standardised method NF EN 15549). Only, the atmospheric concentrations obtained for few compounds (namely, 9-nitroanthracene, 2-nitropyrene, 6nitrobenzo[a]pyrene, 9-phenanthrenecarboxaldehyde, 9,10anthraquinone, benzo[a]fluorenone, benzo[b]fluorenone and benzanthrone) were statistically different (at least at one sampling site). A combination of several processes could explain the differences observed. First, the reduce pressure on the lower impactor stages could induce the desorption of the more volatiles compounds, especially in summer season (Zhang and McMurry, 1991; Di Filippo et al., 2010, and references therein). Second, the difference of technology between both samplers could play a role in the disparities observed. The contact between collected particles and ambient air is probably greater in the case of the DA-80 (filtration) and the backup filter of the MOUDI sampler than for the impactor stages. In the case of the MOUDI, the airflow just runs over the sampling media (aluminium foils), while for the DA-80, the airflow pass through the filter inducing that sampled particles are more exposed to atmospheric oxidants. The formation of secondary compounds is then potentially higher using filtration sampling systems (Albinet et al., 2007b; Sanderson and Farant, 2005). Additionally, degradation of some compounds by reaction with atmospheric oxidants $\left(\mathrm{O}_{3}, \mathrm{NO}_{\mathrm{x}}, \mathrm{OH}\right)$ could be also higher using this system. As an example, the secondary formation of 1,4anthraquinone has never been reported but its degradation, in the presence of atmopheric oxidants, was recently observed (Ringuet et al., 2012b).

Nevertheless, all the results showed here were obtained using the same cascade impactor sampler, the same analytical procedure and equipment inducing that the total measurement error made could be considered as systematic. NPAH and OPAH particle size distributions obtained during both sampling campaigns could be compared and discussed with a high level of confidence.

\subsection{Particulate NPAH and OPAH concentration levels}

A detailed analysis and a discussion about the atmospheric polycyclic aromatic compound (PAC) concentrations, PAC profiles and their relationships with other pollutants, could be found in a previous paper (Ringuet et al., 2012a). Here we only briefly discuss the results obtained about NPAH and OPAH concentration levels (Table 1).

OPAH and NPAH concentration levels observed were largely higher at the traffic site $\left(\approx 1 \mathrm{ng} \mathrm{m}^{-3}\right.$ and $0.2 \mathrm{ng} \mathrm{m}^{-3}$

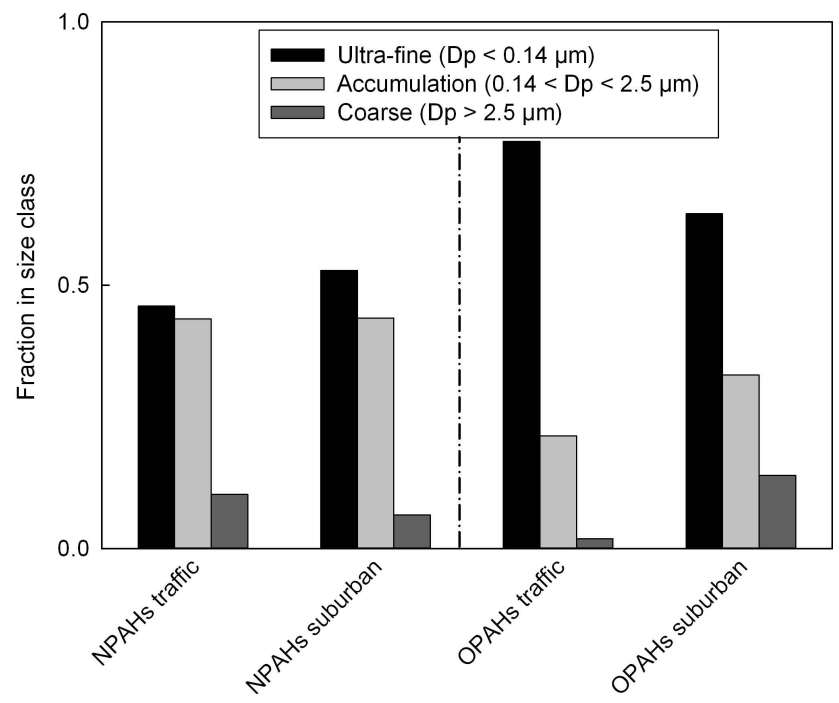

Fig. 1. Average NPAH and OPAH concentration fractions in the different particle size classes at the traffic and suburban sites. The percentage of NPAHs and OPAHs in each size class is based on the total OPAH and NPAH concentrations.

for OPAHs and NPAHs, respectively), than at the suburban site $\left(<0.1 \mathrm{ng} \mathrm{m}^{-3}\right.$ and $0.02 \mathrm{ng} \mathrm{m}^{-3}$, for OPAHs and NPAHs, respectively). All these results were in good agreement with previous studies performed on similar sites and season (summer) (e.g. Albinet et al., 2007a, 2008b; Bamford and Baker, 2003; Di Filippo et al., 2009; Kojima et al., 2010; Liu et al., 2006; Schnelle-Kreis et al., 2001).

Few compounds (2-nitrofluorene, 6-nitrochrysene and 1,6dinitropyrene) were not quantified in sufficient amount in order to establish their full particle size distributions and are not showed here.

\subsection{NPAH and OPAH concentrations and profiles in the different size classes}

Particulate matter is usually divided in three size classes according to particle formation processes: the ultra-fine mode $\left(D_{\mathrm{p}}<0.14 \mu \mathrm{m}\right)$, the accumulation mode $\left(0.14 \mu \mathrm{m}<D_{\mathrm{p}}<2.5 \mu \mathrm{m}\right)$ and the coarse mode $\left(D_{\mathrm{p}}>2.5 \mu \mathrm{m}\right)$ (Whitby, 1978). This repartition is also closely linked to the sanitary impact of the particles. The NPAH and OPAH fraction in the different size classes is presented on Fig. 1 for both sites. The percentage of NPAHs and OPAHs in each size class is based on the total OPAH and NPAH concentrations.

The part of OPAHs and NPAHs associated to particles smaller than $2.5 \mu \mathrm{m}$ was upper than $85 \%$, at both sites (Fig. 1), showing that a large part of these compounds are able to reach the deepest part of the human respiratory system and highlighting the importance to study this class of compounds from a sanitary point of view. 


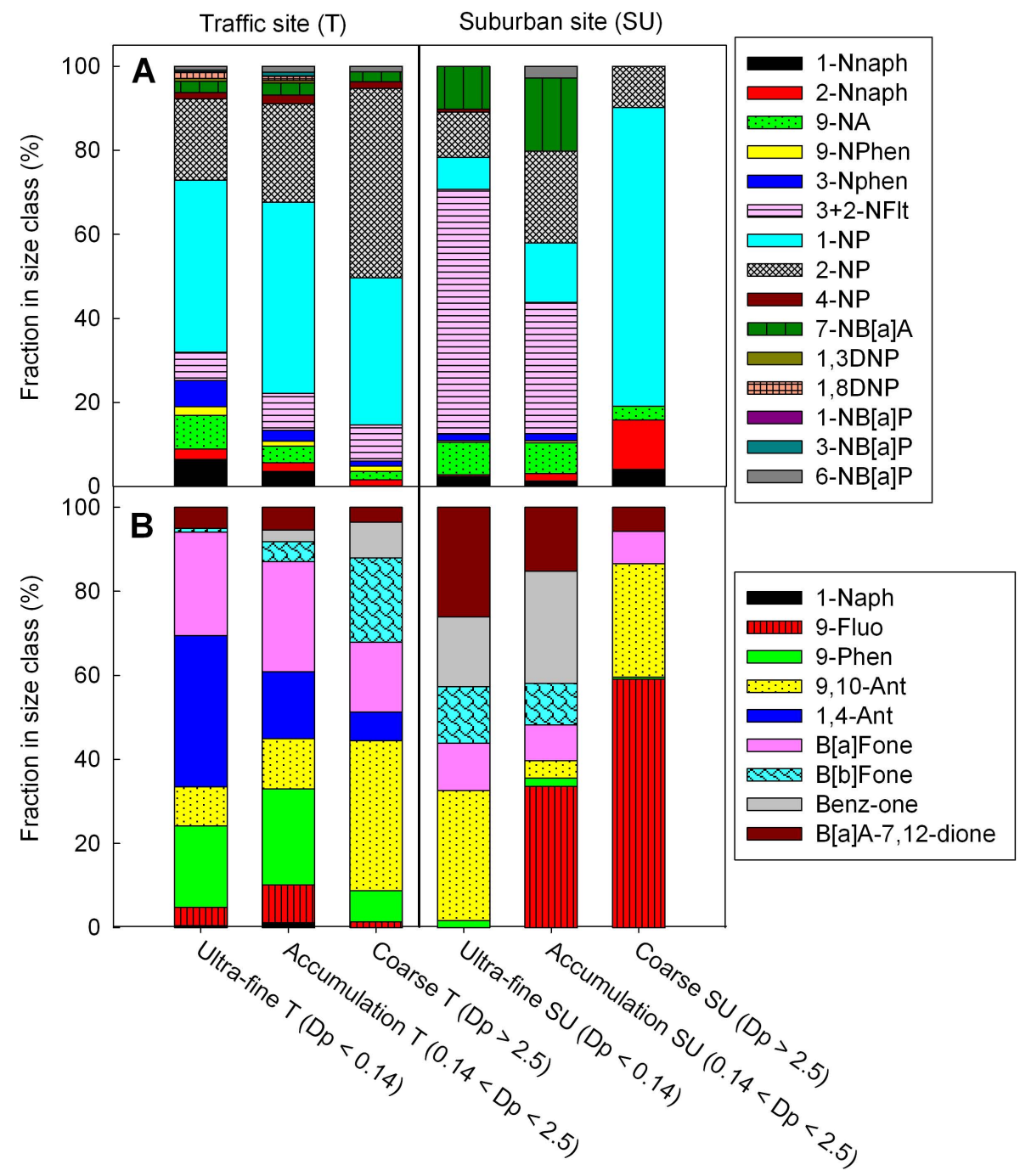

Fig. 2. NPAH (A) and OPAH (B) concentration profiles (\%) according to the different particle size classes and to the sampling site (traffic and suburban).

The fraction of NPAHs in the different size classes was almost the same at both sites. The ultra-fine and accumulation modes were of the same order of magnitude $(\approx 50 \%$ of the sum of NPAH), while less than $10 \%$ of NPAHs were associated to the coarse particulate fraction. These findings were not in agreement with previous studies where NPAHs sampled on traffic sites were mostly associated to the accumulation mode (Kawanaka et al., 2008; Albinet et al., 2008a). Unlike NPAHs, the ultra-fine mode was highly predominant for OPAHs at both, the traffic and the suburban site (77 and $64 \%$, respectively). Coarse mode was largely lower, especially at the traffic site (2\%). Differences of particle size distributions between OPAHs and NPAHs were in total agreement with the literature (Albinet et al., 2008a) and showed that, at least in summer season, OPAHs were more associated to the finest fraction of aerosol particles than NPAHs even at the traffic site. Differences of sources (see paragraph 4.
Discussion) and/or differences of chemical affinity between OPAHs and NPAHs could explain these observations as already suggested by previous authors (Albinet et al., 2008a).

In order to apprehend the sanitary impact of NPAHs and OPAHs and to evaluate the link between their origin (primary and/or secondary) and their particle size distribution, it could be interesting to study the chemical profiles of these toxic compounds according to their particle size class (Fig. 2). Observed NPAH and OPAH profiles were strongly different between both studied sites and this, whatever the particle size class considered. This result highlighted a difference of source influences (Ringuet et al., 2012a).

At traffic site, NPAH profiles observed in the ultra-fine and accumulation modes were similar. 1-Nitropyrene $(\approx 40 \%$ of the total particulate NPAH concentration) was predominant while, in the coarse mode, both 1- and 2-nitropyrene were the most abundant NPAHs $(\approx 40 \%$ each). As for NPAHs, 
OPAH ultra-fine and accumulation profiles observed at the traffic site were quite comparable. Benzo[a]fluorenone and 9phenanthrenecarboxaldehyde accounted each for about $20 \%$ of the total particulate OPAH concentrations. Coarse mode profile was largely different with a predominance of 9,10anthraquinone and benzo[b]fluorenone $(\approx 35$ and $20 \%$, respectively), and a minor contribution of 1,4-anthraquinone and 9-phenanthrenecarboxaldehyde $(\approx 5 \%)$. Interestingly, 1,4-anthraquinone contribution decreased with the increase of the particle size class. It accounted about $40 \%$ of the total OPAH concentration in the ultra-fine mode while, it represented about $15 \%$ in the accumulation mode and less than $5 \%$ in the coarse mode.

Contrary to the traffic site, profiles of both, NPAHs and OPAHs, in each particle size class were different at the suburban site. 2+3-Nitrofluoranthene was predominant in the ultra-fine and accumulation modes and accounted about 60 and $30 \%$ of total NPAH concentration while, 1nitropyrene $(50 \%)$ was the most abundant NPAH in the coarse mode. For OPAHs, 9,10 -anthraquinone $(\approx 30 \%)$ and benz[a]anthracene-7,12-dione $(\approx 25 \%)$, were predominant in the ultra-fine mode whereas, 9-fluorenone and benzanthrone were the most abundant OPAHs $(\approx 30 \%)$ in the accumulation mode and the contribution of 9,10-anthraquinone was really low $(<2 \%)$. The coarse mode was largely dominated by 9 -fluorenone and 9,10-anthraquinone (60 and $30 \%)$. Finally, note that, 1,4-anthraquinone was not detected on this site in any particle size class.

\subsection{Particle size distribution of NPAH and OPAHs}

NPAH and OPAH size distributions were plotted by normalizing the compound concentrations for each stage to the total compound concentration and the logarithmic bin width. The data are represented as $\Delta \mathrm{C} /\left(\mathrm{C}_{\text {total }} \Delta \log D_{\mathrm{p}}\right)$ (Figs. 3, 4 and 5). The lower limit of particle size collected on the backup filter $\left(D_{\mathrm{p}}=0.01 \mu \mathrm{m}\right)$ has been selected arbitrarily.

NPAH and OPAH are compounds partitioned in both, gaseous and particulate phases. Their partitioning is strongly dependent on their molecular weight and their vapour pressure (Albinet et al., 2007a, 2008b; Allen et al., 1997; Sanderson and Farant, 2005). The lighter compounds are in the gaseous phase or partitioned between both phases whereas, the heaviest OPAHs and NPAHs are only associated to the particulate matter. In this way, it could be interesting to study the particle size distribution of NPAHs and OPAHs according to their molecular weight and so, their predominance in gaseous or in particulate phase (Fig. 3).

The particle size distributions of the sum of low molecular weight NPAHs (LWNPAHs; MW $\leq 223 \mathrm{~g} \mathrm{~mol}^{-1}$, from 1-nitronaphthalene to 3-nitrophenanthrene) and high molecular weight NPAHs (HWNPAHs; $\mathrm{MW} \geq 247 \mathrm{~g} \mathrm{~mol}^{-1}$, from 2+3-nitrofluoranthene to 6-nitrobenzo[a]pyrene) and some selected NPAHs of different molecular weight are presented in Figs. 3 and 4.

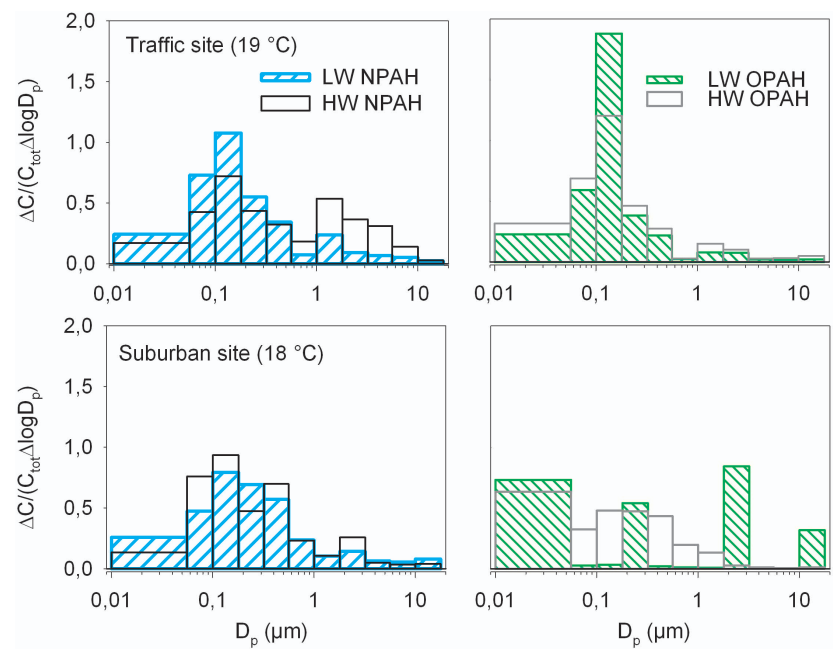

Fig. 3. Particle size distributions at traffic and suburban sites of $\sum$ NPAHs and $\sum$ OPAHs according to their molecular weight range (LWNPAHs: $\mathrm{MW} \leq 223 \mathrm{~g} \mathrm{~mol}^{-1}$; HWNPAHs: $\mathrm{MW} \geq 247 \mathrm{~g} \mathrm{~mol}^{-} 1$ and LWOPAHs: $\mathrm{MW} \leq 208 \mathrm{~g} \mathrm{~mol}^{-1}$; HWOPAHs: $\mathrm{MW} \geq 230 \mathrm{~g} \mathrm{~mol}^{-1}$ ).

At the traffic site, particle size distributions of both, LWNPAHs and HWNPAHs, were clearly bimodal (modes centred at $D_{\mathrm{p}}=0.14$ and $1.4 \mu \mathrm{m}$ ) with a large contribution of LWNPAHs to the first mode (1-nitronaphtalene (1-Nnaph) and 9nitroanthracene (9-NA)) while, the second mode was mainly attributable to HWNPAHs (2+3-nitrofluoranthene $(2+3-\mathrm{NF})$ and 1-nitropyrene (1-NP)). Interestingly, this result disagreed with previous studies performed in similar conditions (traffic site in summer period) (Albinet et al., 2008a) where NPAH distributions were reported as unimodal and centered at $D_{\mathrm{p}}=0.8 \mu \mathrm{m}$. A difference in number and nature of source influences between these sites considered as "traffic" could explain these observations.

Particle size distributions at the suburban site were more scattered due to the low concentration of several NPAHs. The predominant mode was around $0.14 \mu \mathrm{m}$ for both, HWNPAHs and LWNPAHs, and a little mode was observed in the super micrometre fraction at $1.4 \mu \mathrm{m}$. The observed distributions here seemed more similar (and especially for 9nitroanthracene (9-NA)) to the results reported for a site downtown Rome (Italy) where the distributions of some NPAHs were bimodal (both in the sub micrometre fraction) with a major mode centered at $D_{\mathrm{p}}=0.4 \mu \mathrm{m}$ (Di Filippo et al., 2010). Finally, NPAH size distributions obtained were really different than those observed by Albinet et al. (2008a) on suburban sites in the French Alps.

The size distribution of low molecular weight OPAHs (LWOPAHs; $\mathrm{MW} \leq 208 \mathrm{~g} \mathrm{~mol}^{-1}$, from 1-naphthaldehyde to 1,4-anthraquinone) and high molecular weight OPAHs (HWOPAHs; MW $\geq 230 \mathrm{~g} \mathrm{~mol}^{-1}$, from benzo[a]fluorenone to benz[a]anthracene-7,12-dione) and selected individual OPAHs are presented on Figs. 3 and 5. 


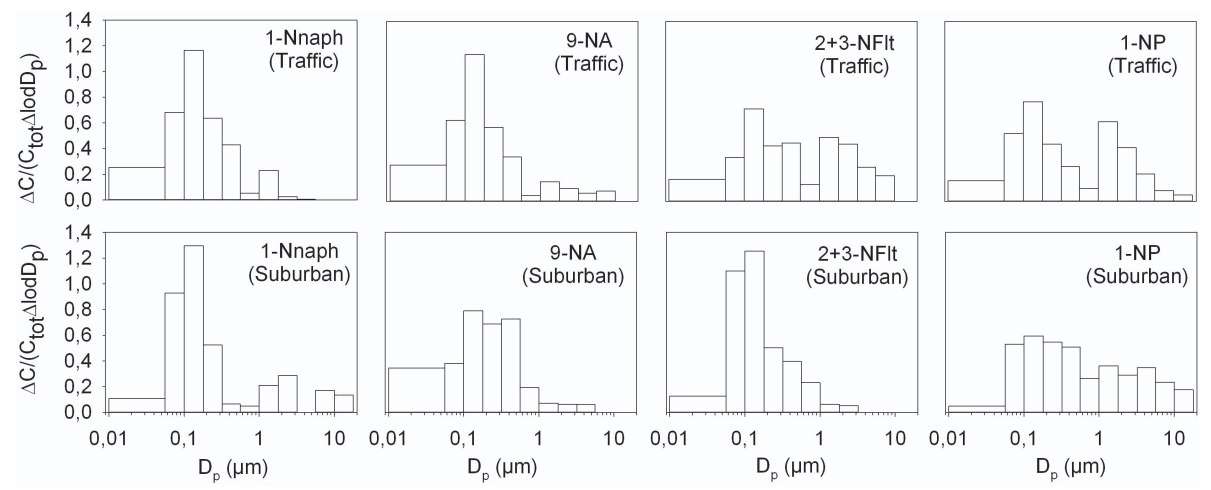

Fig. 4. Particle size distributions of 1-nitronaphthalene (1-Nnaph), 9-nitroanthracene (9-NA), 2+3-nitrofluoranthene (2+3-NFlt) and 1nitropyrene (1-NP) at traffic and suburban sites.
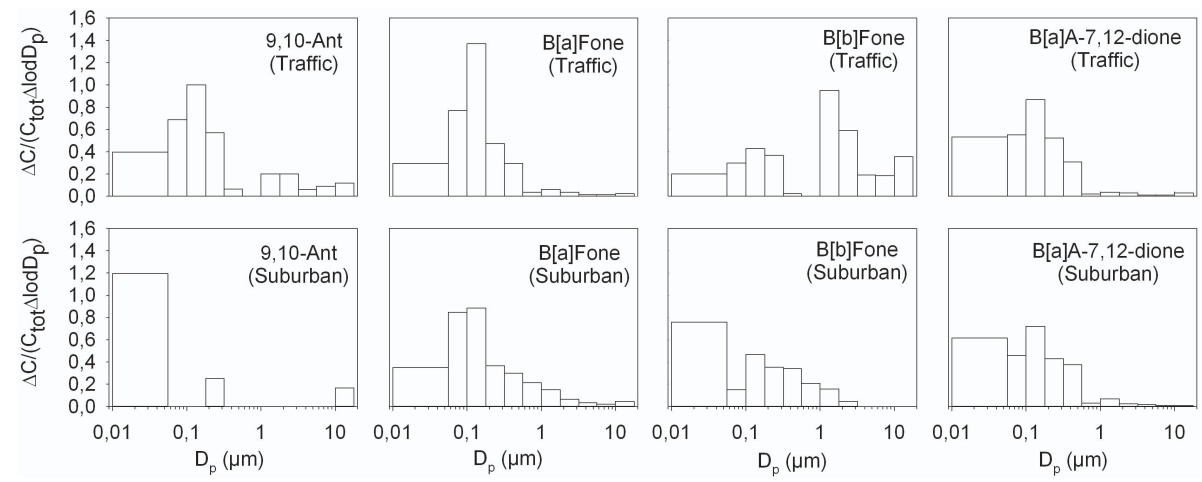

Fig. 5. Particle size distributions of 9,10 -anthraquinone $(9,10-A n t)$, benzo[a]fluorenone (B[a]Fone), benzo[b]fluorenone (B[b]Fone) and benzo[a]anthracene-7,12-dione (B[a]A-7,12-dione) at traffic and suburban sites.

OPAH particle size distributions were also bimodal at the traffic site, but contrary to NPAHs, the second mode $(1.4 \mu \mathrm{m})$ was significantly less important than the one centred at $0.14 \mu \mathrm{m}$. At the suburban site, OPAH particle size distributions were really scattered, particularly for LWOPAHs like 9,10-antraquinone (Fig. 4). Bimodal distributions were observed for HWOPAHs with modes centred at 0.056 and $0.25 \mu \mathrm{m}$ (benzo[b]fluorenone and benz[a]antracen-7,12dione, Fig. 5). All these results were in disagreement with previous studies showing clearly unimodal particle size distributions and an association of OPAHs to larger particles, for both, traffic and suburban sites (Albinet et al., 2008a; Allen et al., 1997). These results highlighted the strong dependence of OPAH particle size distribution with the studied site.

\section{Discussion}

The particle size distribution of PACs depends of various parameters, such as the typology of the sampling site, the physicochemical properties of the compounds or the characteristics of the particles (e.g. origin, age). Fine particles are emitted by combustion processes and/or secondary formation in the atmosphere, whereas coarse particles $(>2.5 \mu \mathrm{m})$ orig- inated from primary non-combustion processes, such as resuspension of surface dust and soil particles by wind action. Once emitted, organic compounds associated to fine particles, including NPAHs and OPAHs, could migrate during their transport in the atmosphere towards larger particles by volatilisation/sorption processes (Venkataraman et al., 1999; Albinet et al., 2008b; Allen et al., 1996, 1997; Venkataraman and Friedlander, 1994). The migration of these compounds depends on their vapour pressure. Lighter PACs have higher vapour pressure than the heavier ones and could be transferred more rapidly towards large particles.

At the suburban site, the particle size distributions of OPAHs (Figs. 3 and 5) and some NPAHs, such as 1nitropyrene (Fig. 4) were spread with a lower definition of the modes than at traffic site. Suburban site was not directly influenced by combustion sources and size distributions observed could be explained by the transfer of PACs from fine to coarse particles during the transport of particles in the atmosphere. Interestingly, isomers of benzofluorenone showed really different particle size distributions at both sites (Fig. 5). Benzo[a]fluorenone size distribution was unimodal while, the one of benzo[b]fluorenone was bimodal. Vapour pressures of both isomers are similar $\left(v p=3.4 \times 10^{-6} \mathrm{~Pa}\right.$, 
sparc online calculator: http://archemcalc.com/sparc/test). The difference of mass transfer from fine to large particles (volatilization/sorption process) was not able to explain the observations made.

The study of the particle size distributions could bring some information on the source of PACs. At traffic site, OPAHs were strongly associated to particles of diameter about $0.14 \mu \mathrm{m}$ (Fig. 1). Previous studies reported that traffic combustion mainly emitted particulate matter in the size range around $0.1 \mu \mathrm{m}$ (Wang et al., 2011; Jones and Harrison, 2006). Results observed showed that traffic (combustion) constitutes a major source of OPAHs. This was consistent with conclusions from a previous paper for the same sampling site (Ringuet et al., 2012a). On the other hand, NPAH particulate size distributions were clearly bimodal $\left(D_{\mathrm{p}}=0.14\right.$ and $1.4 \mu \mathrm{m}$ ). If the first peak could be assigned to the traffic emissions (combustion), the second mode highlighted the existence of another origin of NPAHs. Resuspension of particles accumulated on the road and containing a large part of HWNPAHs (compounds with a low volatility) could be this source as already showed in a previous study (Ringuet et al., 2012a).

The comparison of the particle size distributions of compounds recognized as primary or secondary combined with the comparison of the chemical profiles observed in each particle size class for both sites, brought information about the primary and secondary origin of the NPAHs and OPAHs.

For example, at the suburban site (site far from direct combustion sources), particle size distribution of 1nitropyrene was really different than the one observed for 2+3-nitrofluoranthene while they were similar at the traffic site (Fig. 4). 1-Nitropyrene is known as mainly primary emitted by diesel powered engines (Paputa-Peck et al., 1983) and used as marker of diesel emissions (e.g. Albinet et al., 2007a), whereas 2-nitrofluoranthene (largely predominant against 3-nitrofluoranthene in ambient air (Bamford and Baker, 2003)) is solely secondarily formed (Arey et al., 1986; Atkinson and Arey, 1994; Ringuet et al., 2012b). Differences of size distributions observed between both compounds at the suburban site could be attributed to their difference of origin.

Additionally, the 2-nitrofluoranthene/1-nitropyrene (2NFlt/1-NP) ratio is commonly used by various authors in order to evaluate the importance of secondary formation of NPAHs (e.g. Bamford and Baker, 2003; Albinet et al., 2007a, 2008a and references therein). Assuming the same removal and photolysis rates (Fan et al., 1996), a ratio higher than 5 highlights a significant formation of NPAHs. Note that in this study, the separation of 2- and 3-NFlt could not be achieved with the chromatographic column used $(5 \%$ phenyl-substituted methylpolysiloxane phase). In ambient air, the proportion of 3-NFlt is largely lower than 2-Nflt $[<1 \%$ (Bamford and Baker, 2003; Zielinska et al., 1989) and $<50 \%$ (Feilberg et al., 2001)] allowing to use the 2+3-NF/1NP ratio with caution (Albinet et al., 2007a, 2008b; Ringuet et al., 2012a). Figure 6, shows the 2+3-NFlt/1-NP ratio val-

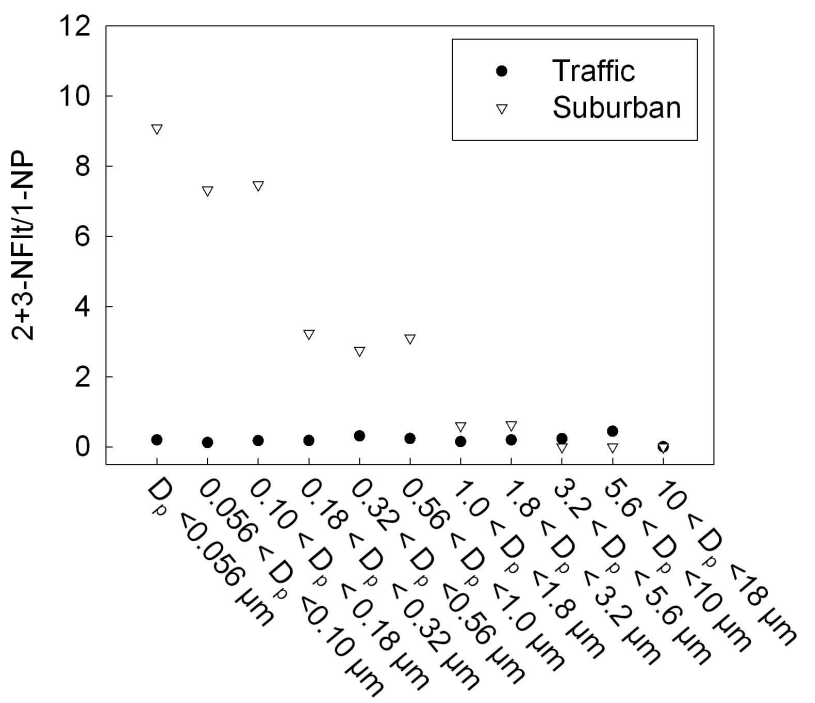

Fig. 6. 2+3-Nitrofluoranthene/1-nitropyrene ratios (2+3-NFlt/1-NP) according to the particle size classes for traffic and suburban sites.

ues calculated in each particle size class for both sampling sites. At the traffic site, ratio values observed were really low in all particle size ranges in agreement with the primary origin of NPAHs at this site (traffic combustion and probably resuspension). At the suburban site, the highest 2+3-NFlt/1NP ratio values were observed for the smallest particles highlighting that NPAHs formed by chemical reactions in the atmosphere condensed on the fine fraction of the aerosol particles, and more precisely on ultra-fine particles, because of their greater specific surface.

All these results were consistent with PAC profiles observed in each particle size mode (Fig. 2). The similar and constant profiles observed for NPAHs and, the predominance of 1-NP in the ultra-fine and accumulation modes at the traffic site (Fig. 2) were coherent with the fact that the traffic (combustion) constituted the main source of NPAHs at this site. At the suburban site, the high variability of the profiles between each size class was consistent with the ageing process of the aerosol during the transport of the particles in the atmosphere. Moreover, 2+3-nitrofluoranthene was found as predominant and only associated to the ultrafine and accumulation modes, in link with its secondary formation in the atmosphere and its quick condensation on the small particles. Same conclusions could be made for the 7-nitrobenz[a]anthracene, benz[a]antracene-7,12-dione and benzo[b]fluorenone previously described as secondary formed by heterogeneous reaction processes with $\mathrm{O}_{3}$ and/or $\mathrm{NO}_{2}$ (Ringuet et al., 2012b). Interestingly, at the traffic site, the part of 1,4-anthraquinone decreased the size of the particles increased highlighting that this OPAH is only emitted by combustion engines. This result was consistent with previous studies, in which 1,4-anthraquinone was not observed as a degradation product of anthracene (Perraudin et 
al., 2007; Ringuet et al., 2012b). Interestingly, 9-fluorenone and 9,10-anthraquinone were largely abundant in the coarse mode for the suburban site. This result could be due to the slowest volatilization/sorption process of OPAHs (in regard to NPAHS or PAHs) inducing that, the HWOPAHs remain associated to smaller particles, as observed in previous studies (Albinet, 2006; Allen et al., 1996).

\section{Conclusions}

NPAH and OPAH particle size distributions were established for two sites of different typologies (traffic and suburban). Overall, these toxic compounds were mainly associated (about $85 \%$ ) with the fine particles $\left(D_{\mathrm{p}}<2.5 \mu \mathrm{m}\right)$ highlighting the importance of their study in ambient air.

At traffic site, particle size distributions were found as bimodal with peaks centred at 0.14 and $1.4 \mu \mathrm{m}$ with a strong contribution of heavy NPAHs (HWNAPHs) to the supermicrometre fraction. At the suburban site, particle size distributions were more scattered due to volatilization/sorption processes occurring during aerosol ageing. Results showed that a detailed and combined study of particle size distributions applied to some marker compounds and to NPAH or OPAH chemical profiles could bring information on their primary and/or secondary origin. The secondary formation of OPAH and NPAH was evident at the suburban site and the compounds formed were only associated to the fine particles $\left(D_{\mathrm{p}}<2.5 \mu \mathrm{m}\right)$. At the traffic site, compounds emitted by vehicles were mainly associated to the finest aerosol particles $\left(D_{\mathrm{p}}<0.14 \mu \mathrm{m}\right)$ but the presence of an important second mode in the super micrometre fraction, notably for HWNPAHs, highlighted the existence of a phenomenon of particle resuspension.

\section{Supplementary material related to this article is available online at: http://www.atmos-chem-phys.net/12/ 8877/2012/acp-12-8877-2012-supplement.pdf.}

Acknowledgements. The authors wish to thank the French Ministries of Environment and of Research for their financial support, Airparif for the sampling campaign, INERIS analytical resources (Nadine Guillaumet and Hugues Biaudet).

Edited by: A. Baklanov

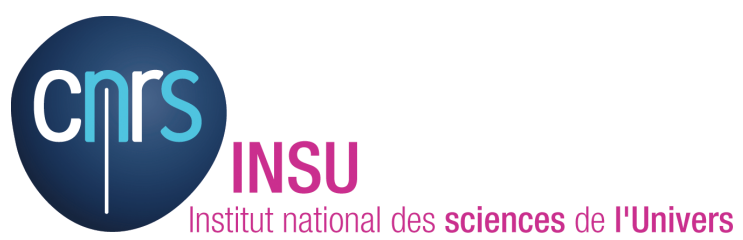

The publication of this article is financed by CNRS-INSU.

\section{References}

Albinet, A.: Hydrocarbures aromatiques polycycliques et leurs dérivés nitrés et oxygénés dans l'air ambiant: caractérisation physico-chimique et origine (French language), Université Bordeaux 1, 408 pp., 2006.

Albinet, A., Leoz-Garziandia, E., Budzinski, H., and Villlenave, E.: Simultaneous analysis of oxygenated and nitrated polycyclic aromatic hydrocarbons on standard reference material 1649a (urban dust) and on natural ambient air samples by gas chromatographymass spectrometry with negative ion chemical ionisation, J. Chromatogr., A, 1121, 106-113, 2006.

Albinet, A., Leoz-Garziandia, E., Budzinski, H., and Villlenave, E.: Polycyclic aromatic hydrocarbons (PAHs), nitrated PAHs and oxygenated PAHs in ambient air of the Marseilles area (South of France): concentrations and sources, Sci. Total Environ., 384, 280-292, 2007a.

Albinet, A., Leoz-Garziandia, E., Budzinski, H., and Villlenave, E.: Sampling precautions for the measurement of nitrated polycyclic aromatic hydrocarbons in ambient air, Atmos. Environ., 41, 4988-4994, 2007b.

Albinet, A., Leoz-Garziandia, E., Budzinski, H., Villenave, E., and Jaffrezo, J.-L.: Nitrated and oxygenated derivatives of polycyclic aromatic hydrocarbons in the ambient air of two French alpine valleys Part 2: Particle size distribution, Atmos. Environ., 42, 5564, 2008a.

Albinet, A., Leoz-Garziandia, E., Budzinski, H., Villenave, E., and Jaffrezo, J.-L.: Nitrated and oxygenated derivatives of polycyclic aromatic hydrocarbons in the ambient air of two French alpine valleys: Part 1: Concentrations, sources and gas/particle partitioning, Atmos. Environ., 42, 43-54, 2008b.

Allen, J. O., Dookeran, N. M., Smith, K. A., Sarofim, A. F., Taghizadeh, K., and Lafleur, A. L.: Measurement of polycyclic aromatic hydrocarbons associated with size-segregated atmospheric aerosols in Massachusetts, Environ. Sci. Technol., 30, 1023-1031, 1996.

Allen, J. O.: Atmospheric partitioning of polycyclic aromatic hydrocarbons (PAH) and oxygenated PAH, 345 pp., 1997.

Allen, J. O., Dookeran, N. M., Taghizadeh, K., Lafleur, A. L., Smith, K. A., and Sarofim, A. F.: Measurement of oxygenated polycyclic aromatic hydrocarbons associated with a size-segregated urban aerosol, Environ. Sci. Technol., 31, 2064-2070, 1997.

Arey, J., Zielinska, B., Atkinson, R., Winer, A. M., Ramdahl, T., and Pitts Jr., J. N.: The formation of nitro-PAH from the gasphase reactions of fluoranthene and pyrene with the $\mathrm{OH}$ radical in the presence of $\mathrm{NO}_{\mathrm{x}}$, Atmos. Environ., 20, 2339-2345, 1986.

Arey, J., Zielinska, B., Harger, W. P., Atkinson, R., and Winer, A. M.: The contribution of nitrofluoranthenes and nitropyrenes to the mutagenic activity of ambient particulate organic-matter collected in Southern-California, Mutat. Res., 207, 45-51, 1988.

Atkinson, R.: Gas-phase tropospheric chemistry of organiccompounds - A review, Atmos. Environ., 24, 1-41, 1990.

Atkinson, R. and Arey, J.: Atmospheric chemistry of gasphase polycyclic aromatic-hydrocarbons - Formation of atmospheric mutagens, Environ. Health Perspect., 102, 117-126, doi:10.2307/3431940, 1994.

Bamford, H. A. and Baker, J. E.: Nitro-polycyclic aromatic hydrocarbon concentrations and sources in urban and suburban atmospheres of the Mid-Atlantic region, Atmos. Environ., 37, 20772091, 2003. 
Berico, M., Luciani, A., and Formignani, M.: Atmospheric aerosol in an urban area-measurements of TSP and $\mathrm{PM}_{10}$ standards and pulmonary deposition assessments, Atmos. Environ., 31, 36593665, 1997.

Cecinato, A., Marino, F., Di Filippo, P., Lepore, L., and Possanzini, M.: Distribution of n-alkanes, polynuclear aromatic hydrocarbons and nitrated polynuclear aromatic hydrocarbons between the fine and coarse fractions of inhalable atmospheric particulates, J. Chromatogr., A, 846, 255-264, 1999.

Di Filippo, P., Riccardi, C., Pomata, D., Gariazzo, C., and Buiarelli, F.: Seasonal abundance of particle-phase organic pollutants in an urban/industrial atmosphere, Water, Air, Soil Pollut., 211, 231250, 2009.

Di Filippo, P., Riccardi, C., Pomata, D., and Buiarelli, F.: Concentrations of PAHs, and nitro- and methyl-derivatives associated with a size-segregated urban aerosol, Atmos. Environ., 44, 27422749, 2010.

Duan, J. C., Bi, X. H., Tan, J. H., Sheng, G. Y., and Fu, J. M.: The differences of the size distribution of polycyclic aromatic hydrocarbons (PAHs) between urban and rural sites of Guangzhou, China, Atmos. Res., 78, 190-203, 2005.

Durant, J. L., Busby, W. F., Lafleur, A. L., Penman, B. W., and Crespi, C. L.: Human cell mutagenicity of oxygenated, nitrated and unsubstituted polycyclic aromatic hydrocarbons associated with urban aerosols, Mutat. Res., 371, 123-157, 1996.

Fan, Z. H., Kamens, R. M., Hu, J. X., Zhang, J. B., and McDow, S.: Photostability of nitro polycyclic aromatic hydrocarbons on combustion soot particles in sunlight, Environ. Sci. Technol., 30, 1358-1364, 1996.

Feilberg, A., B. Poulsen, M. W., Nielsen, T., and Skov, H.: Occurrence and sources of particulate nitro-polycyclic aromatic hydrocarbons in ambient air in Denmark, Atmos. Environ., 35, 353 366,2001

Hayakawa, K., Kawaguchi, Y., Murahashi, T., and Miyazaki, M.: Distribution of nitropyrenes and mutagenicity in airborne particulates collected with an Andersen sampler, Mutat. Res. Lett., 348, 57-61, 1995a.

Hayakawa, K., Murahashi, T., Butoh, M., and Miyazaki, M.: Determination of 1,3-dinitropyrene, 1,6-dinitropyrene, and 1,8-dinitropyrene and 1-nitropyrene in urban air by highperformance liquid-chromatography using chemiluminescence detection, Environ. Sci. Technol., 29, 928-932, 1995 b.

Ishii, S., Hisamatsu, Y., Inazu, K., Kobayashi, T., and Aika, K.I.: Mutagenic nitrated benzo[a]pyrene derivatives in the reaction product of benzo[a]pyrene in $\mathrm{NO}_{2}$-air in the presence of $\mathrm{O}_{3}$ or under photoirradiation, Chemosphere, 41, 1809-1819, 2000.

Jinhui, X. and Lee, F. S. C.: Quantification of nitrated polynuclear aromatic hydrocarbons in atmospheric particulate matter, Anal. Chim. Acta, 416, 111-115, 2000.

Jones, A. M. and Harrison, R. M.: Estimation of the emission factors of particle number and mass fractions from traffic at a site where mean vehicle speeds vary over short distances, Atmos. Environ., 40, 7125-7137, 2006.

Kawanaka, Y., Matsumoto, E., Sakamoto, K., Wang, N., and Yun, S.-J.: Size distributions of mutagenic compounds and mutagenicity in atmospheric particulate matter collected with a lowpressure cascade impactor, Atmos. Environ., 38, 2125-2132, 2004.
Kawanaka, Y., Matsumoto, E., Wang, N., Yun, S.-J., and Sakamoto, K.: Contribution of nitrated polycyclic aromatic hydrocarbons to the mutagenicity of ultrafine particles in the roadside atmosphere, Atmos. Environ., 42, 7423-7428, 2008.

Kojima, Y., Inazu, K., Hisamatsu, Y., Okochi, H., Baba, T., and Nagoya, T.: Influence of secondary formation on atmospheric occurrences of oxygenated polycyclic aromatic hydrocarbons in airborne particles, Atmos. Environ., 44, 2873-2880, 2010.

Ladji, R., Yassaa, N., Balducci, C., Cecinato, A., and Meklati, B. Y.: Distribution of the solvent-extractable organic compounds in fine $\left(\mathrm{PM}_{1}\right)$ and coarse $\left(\mathrm{PM}_{10}\right)$ particles in urban, industrial and forest atmospheres of Northern Algeria, Sci. Total Environ., 408, 415-424, 2009.

Liu, Y., Sklorz, M., Schnelle-Kreis, J., Orasche, J., Ferge, T., Kettrup, A., and Zimmermann, R.: Oxidant denuder sampling for analysis of polycyclic aromatic hydrocarbons and their oxygenated derivates in ambient aerosol: Evaluation of sampling artefact, Chemosphere, 62, 1889-1898, 2006.

Macé, T., Lalere, B., Labarraque, G., Ravantos, C., LeozGarziandia, E., Alleman, L., and Mathé, F.: Rédaction de guides pratiques de calcul d'incertitudes et formation des AASQA - Estimation des incertitudes sur les mesurages des B[a]P réalisés sur site dans la fraction $\mathrm{PM}_{10}$ (3/5) (French language), LCSQA/INERIS/LNE/EMD, http://www.lcsqa.org/system/files/ guides_incertitude_partie3_lne_nov2010_v2.pdf, 2010.

Miguel, A. H., Eiguren-Fernandez, A., Jaques, P. A., Froines, J. R., Grant, B. L., Mayo, P. R., and Sioutas, C.: Seasonal variation of the particle size distribution of polycyclic aromatic hydrocarbons and of major aerosol species in Claremont, California, Atmos. Environ., 38, 3241-3251, 2004.

Oberdörster, G., Oberdörster, E., and Oberdörster, J.: Nanotoxicology: an emerging discipline evolving from studies of ultrafine particles, Environ. Health Perspect., 113, 823-839, 2005.

Paputa-Peck, M. C., Marano, R. S., Schuetzle, D., Riley, T. L., Hampton, C. V., Prater, T. J., Skewes, L. M., Jensen, T. E., and Ruehle, P. H.: Determination of nitrated polynuclear aromatic hydrocarbons in particulate extracts by using capillary column gas chromatography with nitrogen selective detection, Anal. Chem., 55, 1946-1954, 1983.

Pedersen, D. U., Durant, J. L., Penman, B. W., Crespi, C. L., Hemond, H. F., Lafleur, A. L., and Cass, G. R.: Human-cell mutagens in respirable airborne particles in the northeastern United States. 1. Mutagenicity of fractionated samples, Environ. Sci. Technol., 38, 682-689, 2004.

Pedersen, D. U., Durant, J. L., Taghizadeh, K., Hemond, H. F., Lafleur, A. L., and Cass, G. R.: Human cell mutagens in respirable airborne particles from the northeastern United States. 2. Quantification of mutagens and other organic compounds, Environ. Sci. Technol., 39, 9547-9560, 2005.

Perraudin, E., Budzinski, H., and Villenave, E.: Identification and quantification of ozonation products of anthracene and phenanthrene adsorbed on silica particles, Atmos. Environ., 41, 60056017, 2007.

Pitts Jr, J. N., Van Cauwenberghe, K. A., Grosjean, D., Schmid, J. P., Fitz, D. R., Belser, W. L., Knudson, G. P., and Hynds, P. M.: Atmospheric reactions of polycyclic aromatic hydrocarbons: facile formation of mutagenic nitro derivatives, Science, 202, 515-519, 1978. 
Ringuet, J., Albinet, A., Leoz-Garziandia, E., Budzinski, H., and Villenave, E.: Diurnal/nocturnal concentrations and sources of particulate-bound PAHs, OPAHs and NPAHs at traffic and suburban sites in the region of Paris (France) Sci. Total Environ., 437, 297-305, 2012a.

Ringuet, J., Albinet, A., Leoz-Garziandia, E., Budzinski, H., and Villenave, E.: Reactivity of polycyclic aromatic compounds (PAHs, NPAHs and OPAHs) adsorbed on natural aerosol particles exposed to atmospheric oxidants, Atmos. Environ., 61, 1522, 2012b.

Saarnio, K., Sillanpää, M., Hillamo, R., Sandell, E., Pennanen, A. S., and Salonen, R. O.: Polycyclic aromatic hydrocarbons in sizesegregated particulate matter from six urban sites in Europe, Atmos. Environ., 42, 9087-9097, 2008.

Sanderson, E. G. and Farant, J. P.: Atmospheric size distribution of PAHs: Evidence of a high-volume sampling artifact, Environ. Sci. Technol., 39, 7631-7637, 2005.

Schnelle-Kreis, J., Gebefugi, I., Welzl, G., Jaensch, T., and Kettrup, A.: Occurrence of particle-associated polycyclic aromatic compounds in ambient air of the city of Munich, Atmos. Environ., 35, S71-S81, 2001.

Teixeira, E. C., Garcia, K. O., Meincke, L., and Leal, K. A.: Study of nitro-polycyclic aromatic hydrocarbons in fine and coarse atmospheric particles, Atmos. Res, 101, 631-639, 2011.

Venkataraman, C. and Friedlander, S. K.: Size distributions of polycyclic aromatic-hydrocarbons and elemental carbon.2. Ambient measurements and effects of atmospheric processes, Environ. Sci. Technol., 28, 563-572, 1994.
Venkataraman, C., Thomas, S., and Kulkarni, P.: Size distributions of polycyclic aromatic hydrocarbons-gas-particle partitioning to urban aerosols, J. Aerosol Sci., 30, 759-770, 1999.

Venkataraman, C., Negi, G., Brata Sardar, S., and Rastogi, R.: Size distributions of polycyclic aromatic hydrocarbons in aerosol emissions from biofuel combustion, J. Aerosol Sci., 33, 503-518, 2002.

Vione, D., Barra, S., De Gennaro, G., De Rienzo, M., Gilardoni, S., Perrone, M. G., and Pozzoli, L.: Polycyclic aromatic hydrocarbons in the atmosphere: monitoring, sources, sinks and fate. II: Sinks and fate, Ann. Chim., 94, 257-268, 2004.

Wang, X., Westerdahl, D., Wu, Y., Pan, X., and Zhang, K. M.: Onroad emission factor distributions of individual diesel vehicles in and around Beijing, China, Atmos. Environ., 45, 503-513, 2011.

Whitby, K. T.: Physical characteristics of sulfur aerosols, Atmos. Environ., 12, 135-159, 1978.

Zhang, X. Q. and McMurry, P. H.: Theoretical analysis of evaporative losses of adsorbed or absorbed species during atmospheric aerosol sampling, Environ. Sci. Technol., 25, 456-459, 1991.

Zhang, Y., Yang, B., Gan, J., Liu, C., Shu, X., and Shu, J.: Nitration of particle-associated PAHs and their derivatives (nitro-, oxy-, and hydroxy-PAHs) with $\mathrm{NO}_{3}$ radicals, Atmos. Environ., 45, 2515-2521, 2011.

Zielinska, B., Arey, J., Atkinson, R., and Wiener, A. M.: The nitroarenes of molecular weight 247 in ambient particulate samples collected in Southern California, Atmos. Environ., 23, 223-229, 1989. 